\title{
Genetics in cardiovascular diseases
}

\author{
Rudy Celeghin, Gaetano Thiene, Barbara Bauce, Cristina Basso, Kalliopi Pilichou
}

Cardiovascular Pathology Unit, Azienda Ospedaliera, and Department of Cardiac, Thoracic and Vascular Sciences and Public Health, University of Padua, Italy

\begin{abstract}
Cardiovascular diseases (CVDs) are a wide group of disorders affecting the heart and blood vessels, including coronary artery, valve, pericardial, conduction system, myocardial and vascular diseases, either congenital or acquired, which can be also heritable. The advent of next generation sequencing (NGS) was accompanied by quick advances in understanding the genetic basis of human diseases, prompting translation of genetics to the clinic. Precision medicine is based on these findings and on the role of genetic testing to improve the diagnosis, to identify individuals with previously unrecognized disease and family members at risk of future disease development which require longitudinal follow-up. However, the probabilistic nature of genetic testing and the subjectivity of genetic variants classification weighted on current evidence, making this powerful clinical tool difficult to be applied in precision diagnostics and therapeutics. Here, we reviewed systematically the genetic basis of CVDs with special emphasis on the current role of NGS in clinical diagnosis and risk assessment, underlying the need of multidisciplinary cardio-genetic referral centers.
\end{abstract}

\section{Introduction}

The dawn of next-generation sequencing (NGS) technology leads to the storage of massive genome sequence data of patients with rare monogenetic diseases

Correspondence: Cristina Basso, Cardiovascular Pathology Unit, Azienda Ospedaliera; and Department of Cardiac, Thoracic and Vascular Sciences and Public Health, University of Padua, via A. Gabelli 61, 35121 Padua, Italy.

Tel.: +39.0498.212286 - Fax: 0498.272285.

E-mail: cristina.basso@unipd.it

Key words: Cardiovascular diseases; next generation sequencing; genetics.

Contributions: $\mathrm{KP}, \mathrm{RC}$ literature research and manuscript writing; $\mathrm{BB}, \mathrm{GT}, \mathrm{CB}$ manuscript reviewing.

Funding: the authors are supported by the Registry for cardiocerebro-vascular Pathology, Veneto Region, Venice, Italy; Ministry of Health Grant RF-2013-02356762 and RF-201400000394; Veneto Region Target Research, Venice 933/2015; PRIN Ministry of Education, University and Research 2017 3ZWACS, Rome, Italy; and University Research Grants CPDA144300 and BIRD162733, Padua, Italy and A.R.C.A., Associazione Ricerche Cardiopatie Aritmiche (http://www.arcacuore.it/)

Conflict of interests: the authors declare no potential conflict of interests.

Received for publication: 23 April 2019.

Accepted for publication: 23 May 2019.

This work is licensed under a Creative Commons Attribution NonCommercial 4.0 License (CC BY-NC 4.0).

${ }^{\circ}$ Copyright: the Author(s), 2019

Licensee PAGEPress, Italy

Italian Journal of Medicine 2019; 13:137-151

doi:10.4081/itjm.2019.1186 as well as complex disorders, paving the way for personalized medicine. Mendelian cardiovascular diseases (CVDs) include familial hypercholesterolemia, cardiomyopathies, primary arrhythmias syndromes, thoracic aortic aneurysms and dissections and some congenital heart diseases (CHD). The scientific community consensus attributes to genetic testing a leading role for the disease management and genetic counselling to identify asymptomatic family members at risk of developing some diseases. ${ }^{1}$ As such here, we summarize the current findings and applications of NGS in cardiovascular medicine.

\section{Coronary artery disease}

Atherosclerotic coronary artery disease (CAD) is the leading cause of mortality in adults (older than 35 years) worldwide. The risk of developing CAD is modulated by an interplay between genetic and lifestyle factors. ${ }^{2}$ Clinical observations dating back to the ' 50 s support the notion that $50 \%$ of fatal CAD is heritable. ${ }^{3}$ Since 2007, genetic association studies identified about 60 genetic loci linked to $\mathrm{CAD}$, as to prove that the genetics of CAD largely derive from the cumulative effect of multiple common risk alleles. ${ }^{4-6}$ Among the risk factors predisposing to $\mathrm{CAD}$, familial hypercholesterolemia $(\mathrm{FH})$ is the most commonly encountered genetic condition causing high levels of low-density lipoprotein (LDL). Advances in molecular genetics revealed that $\mathrm{FH}$ is more common and complex than previously thought, with the estimated prevalence of heterozygous $\mathrm{FH}$ of $1: 250^{7}$ and homozygous FH up to $1: 300,000 .{ }^{8}$ LDL has manifold deleterious effects on vascular function, including normal 
arterial response to vasodilatatory stimuli, vascular inflammation through multiple mechanisms, and internalization by arterial wall macrophages when LDL particles become oxidized. When overloaded with cholesterol, arterial wall macrophages become foam cells, which are components of the atherosclerotic plaques that can eventually occlude arteries, leading to tissue ischemia. At least 9 different genes have been linked to FH harboring thousands of causative variants, among which LDL-receptor- $L D L R$, apolipoprotein $\mathrm{B}-A P O B^{9,10}$ and microsomal triglyceride transfer-PCSK $9,{ }^{11}$ accounting for $>80 \%, 5-10 \%$ and $\sim 1 \%$ of $\mathrm{FH}$ characterized cases with monogenic basis, respectively (Table 1). Variant types include largescale DNA copy number variations (CNVs, about $10 \%),{ }^{12}$ nonsense mutations within the coding region, missense mutations altering a single amino acid residue, small insertions or deletions (frameshifts) within or near the coding sequence and splicing site mutations occurring at the intron-exon boundaries.

\section{Valvular heart disease}

Valvular heart disease encompasses both congenital and acquired conditions increasing significantly morbidity and mortality worldwide. ${ }^{13}$ Understanding of the mechanism underlying cardiac valve development led to the identification of several genetic etiologies for valvular disease.

Bicuspid aortic valve (BAV) is a congenital valvular defect that affects about $1-2 \%$ of the general population. $^{14,15}$ BAV has an autosomal dominant inheritance with reduced penetrance and variable expressivity. BAV has been described as an isolated trait or associated with syndromic conditions [e.g., Marfan syndrome (MFS), Loeys-Dietz syndrome (LDS) and Turner syndrome]. Complications of BAV may lead to aortic valve stenosis and regurgitation, infective endocarditis, ascending aortic aneurysms and dissection. ${ }^{16-18}$ The first non-syndromic BAV genetic etiology was identified in $\mathrm{NOTCH} 1^{15}$ segregating as autosomal dominant disease in all affected family members. NOTCH1 haploinsufficiency is the main cause found in $\sim 4 \%$ of BAV patients. ${ }^{19-21}$ Recently, GATA4/5 has been linked to aortic valve morphogenesis and endocardial cell differentiation, ${ }^{22-25}$ reduced $U F D 1 L$ gene expression ${ }^{26}$ and involvement of a locus containing AXIN1/PDIA2 $2^{27}$ have shed light on the complex landscape of BAV aided by sequencing technologies advancement (Table 2).

Supravalvular aortic stenosis (SVAS) can be either associated with Williams-Beuren syndrome (characteristic face, behavioral disorders and hypercalcemia) or isolated. The estimated incidence is approximately 1 out of 25,000 births and the mean prevalence in the general population is $1 / 7500$.
Clinical presentation often consists of a systolic murmur that prompts a cardiological screening with ventricular hypertrophy. A progressive hourglass narrowing of the aorta and/or pulmonary artery lumen, is typically detected by echocardiography.

The disease is either sporadic or familial. If familial, it is transmitted as an autosomal dominant trait with incomplete penetrance and variable expressivity. SVAS is caused by a deletion in the elastin-ELN gene, which is located on chromosome 7q11.23. ${ }^{28}$

Mitral valve prolapse (MVP) is considered the most common degenerative valvular heart defect in the general population ( $2 \%-3 \%)$, characterized by abnormal atrial displacement of the MV leaflets during systole. ${ }^{29}$ Genetic basis of MVP syndromic forms are found in MFS which lay mainly on fibrillin1$F B N 1$. To date the only gene linked to non-syndromic MVP in humans is filamin A-FLNA, an intracellular actin-binding filamentous protein with numerous roles in cell migration, scaffolding functions and signaling. ${ }^{30,31}$ However, the disease seems more in keeping with a congenital valvular dystrophy than with the classical MVP. ${ }^{32}$ Finally, murine models with non-syndromic MVP made evident the association of abnormal myxomatous phenotype also with Adams9 and Dchs1 haploinsufficiency. ${ }^{33}$

However, genetic test is not routinely performed for diagnostic purposes in valvular heart disease, with the exception of syndromic forms.

Table 1. Familial hypercholesterolemia.

\begin{tabular}{lc}
\hline Gene & Frequency $(\mathbf{\%})$ \\
\hline$L D L R$ & $80-85$ \\
\hline$A P O B$ & $5-10$ \\
\hline$P C S K 9$ & $\sim 1$ \\
\hline
\end{tabular}

Table 2. Bicuspid aortic valve.

\begin{tabular}{|c|c|}
\hline & Gene \\
\hline \multirow[t]{9}{*}{ Non-syndromic bicuspid aortic valve } & NOTCH1 \\
\hline & GATA5 \\
\hline & GATA4 \\
\hline & ACTA2 \\
\hline & $U F D 1 L$ \\
\hline & $A X I N 1$ \\
\hline & $E N G$ \\
\hline & $E G F R$ \\
\hline & SMAD6 \\
\hline \multirow[t]{8}{*}{ Syndromic bicuspid aortic valve } & FBN1 \\
\hline & $T G F B R 1 / 2$ \\
\hline & ACTA2 \\
\hline & $K C N J 2$ \\
\hline & $E L N$ \\
\hline & $H O X A 1$ \\
\hline & CLO3A1 \\
\hline & 45,X karyotype \\
\hline
\end{tabular}




\section{Aortic disease}

Thoracic (TAA) and abdominal (AAA) aortic aneurysms might exhibit a genetic component in their etiopathogenesis. The prevalence rate of AAA for men $>65$ years old ranges from $1.7 \%$ to $7.2 \%$. Even though various environmental factors have been implicated, a genetic diathesis has been advanced, with family history being one of the strongest risk factors. ${ }^{34}$ TAA and thoracic aortic aneurysm dissection (TAAD) are known to be associated with inherited connective tissue disorders, such as MFS, LDS and vascular EhlersDanlos syndrome (EDS). TAA and TAAD are less common, with an incidence of 10.4 per 100,000 person/year and 2.2 per 100,000 person/year, respectively. ${ }^{35}$ Research studies in these conditions demonstrated that the genetic component is even stronger, with $15 \%$ of patients having a positive family history and exhibiting mostly an autosomal dominant pattern of inheritance with high penetrance. ${ }^{36}$

MFS is a common autosomal dominant disorder $(1: 2000-1: 10,000)$ with a variety of phenotypes and is known to be associated with mitral valve disease, TAA and TAAD. Aortic dilatation in MFS syndrome occurs at the sinuses and the tubular portion of the ascending aorta. In $1991 F B N 1$ was identified as the causative gene which encodes for an extracellular matrix glycoprotein abundantly present in the suspensory ligament of the lens, the periosteum of bone, and the aortic media. ${ }^{37}$ To date more than 1500 distinct $F B N 1$ mutations have been described. ${ }^{38}$ Individual families may have their own private mutation, however family members sharing the same mutation often display a heterogeneous phenotype. Interestingly, $25 \%$ of MFS are caused by de novo mutations. ${ }^{39}$ Mutations of the $F B N 1$ gene may directly affect the structure of the extracellular matrix but they may also have an effect on the transforming growth factor (TGF) $\beta$-binding protein complexes, leading to uncontrolled release of TGF- $\beta$, which has been associated with aneurysm formation. This is an important discovery, as some of the most recent studies on sporadic TAA have also focused on TGF- $\beta$ signaling pathways, suggesting that syndromic and non-syndromic TAA may share, to an extent, a common genetic background. ${ }^{40}$

LDS is a rare autosomal dominant syndromic disorder (unknown incidence) combining the triad of arterial tortuosity and aneurysms throughout the arterial tree, hypertelorism and bifid uvula. ${ }^{41}$ It is characterized by variable expression and aggressive TAAs which can grow 10 times faster than those of MFS. ${ }^{42}$ LDS has been associated with mutation in TGF- $\beta$ receptor-TGFBR, TGF- $\beta$ downstream effector $S M A D 3$, TGF- $\beta 2$ ligand$T G F B 2$, and TGF $\beta 3$ ligand-TGFB3. ${ }^{39,43}$

Vascular type of EDS is a very rare autosomal dominant disorder $(<1: 1,000,000)$ characterized by the risk of spontaneous intestinal, uterine, and arterial rupture as well as joint and cutaneous manifestations. ${ }^{44}$ The culprit gene COL $3 A 1$ encodes for type III procollagen, a component of skin, vessel wall, and hollow organs. ${ }^{45,46}$ The defect results in friable aortic tissue with tears along the aorta and its branches, leading to rupture and dissection often without previous aneurysm and high surgical mortality.

Familial TAAD (FTAAD) represents a group of nonsyndromic disorders characterized by isolated TAAs, without associated systemic features. FTAAD shows an autosomal dominant transmission with great clinical variability and low penetrance. Recently, mutations in genes usually associated with syndromic forms have been reported in FTAAD patients such as MYH11, ACTA2, MYLK, TGFB2, PRKG1. ${ }^{47,48}$ However few data are already available on this new molecular entities and further studies are required (Table 3).

\section{Cardiomyopathies}

Hypertrophic cardiomyopathy (HCM) is the most common inherited cardiomyopathy, defined by the presence of asymmetric left ventricular hypertrophy (LVH) occurring in the absence of known secondary cause, such as hypertension or aortic stenosis, in conjunction with normal global cardiac systolic function and impaired relaxations. ${ }^{49}$ Prevalence is estimated in young adults as about 1 out of 500, with much lower rates in patients $<25$ years of age.$^{50}$ Phenotypic expression of cardiac hypertrophy is age-dependent, and accelerates during puberty and adolescence, typically manifesting by the $3^{\text {rd }}$ and $4^{\text {th }}$ decade of life.

LVH is commonly concentric, involving the interventricular septum, posterior and lateral walls. In about $30-40 \%$ of the patients, hypertrophy predominantly involves the interventricular septum, leading to asymmetric septal hypertrophy. HCM involving predominantly the cardiac apex is present only in a minority of cases. Histologically, cardiac myocyte disarray is the hallmark

Table 3. Aortopathies.

\begin{tabular}{lc}
\hline & Gene \\
\hline Marfan syndrome & FBN1 \\
\hline Loeys-Dietz syndrome & $T G F B R$ \\
& SMAD3 \\
& $T G F B 2$ \\
& TGFB3 \\
\hline Ehlers-Danlos syndrome & COL3A1 \\
\hline Familial thoracic aortic aneurysm dissection & MYH11 \\
& ACTA2 \\
& MYLK \\
& TGFB2 \\
& PRKG1 \\
\hline
\end{tabular}


of HCM and typically occurs in conjunction with myocyte hypertrophy and interstitial fibrosis. Myocyte disarray in HCM typically involves $>20 \%$ of the myocardium and is more prominent in the septum. LVH is defined as $13 \mathrm{~mm}$ or greater left ventricular wall thickness in adults and a z-score $>2$ in children. ${ }^{51}$

The cardinal symptoms are palpitations, pre-syncope, syncope due to ventricular arrhythmias at risk of sudden cardiac death (SCD). The second set of symptoms, which include dyspnea, orthopnea and peripheral edema, are related to diastolic dysfunction and heart failure with preserved ejection fraction. Systolic dysfunction usually occurs at later ages.

HCM exhibits an autosomal dominant mode of inheritance even though sporadic forms have been found in about one third of the cases. ${ }^{52}$ Disease-causing mutations are detected mainly in genes encoding sarcomeric proteins (Table 4). The first missense mutation identified was located on the $\beta$-myosin heavy chainMYH7 gene $^{53}$ and up to date in $75 \%$ of cases an identifiable pathogenic variant is found in myosin binding protein c-MYBPC $3^{54}$ and $M Y H 7$. Less than $10 \%$ of cases carry variants in other genes encoding for the regulatory/essential light chains of the thick filaments (myosin light chain 2-MYL2; myosin light chain 3$M Y L 3)^{55}$ and for sarcomere thin filaments proteins (troponin T-TNNT2; troponin I-TNNI3, troponin C-TNNC1, $\alpha$ tropomyosin-TPM1, $\alpha$ actin- $A C T C 1) .{ }^{56-}$ ${ }^{61}$ Multiple sarcomeric protein mutations are present in up to $5 \%$ of individuals and tend to have a more severe phenotype with earlier onset. Mutations in non-sarcomeric genes could also cause primary cardiac hypertrophy resembling HCM caused by sarcomeric mutations, but the pathophysiology in such conditions is different as such are considered HCM phenocopies. ${ }^{62}$

Approximately $5 \%$ of adults and children with unexplained LVH are secondary HCM, caused by metabolic disorder, mitochondrial diseases, syndromic and neuromuscular diseases. ${ }^{63}$ Many of these conditions are hereditary, mostly displaying as autosomal recessive trait but also X-linked. Cardiac assessment should be an integral part of managing patients with these multisystem diseases, to avoid confusion leading to erroneous diagnoses of a primary cardiomyopathy.

Metabolic disorders, such as glycogen storage diseases, can be caused by mutation in glucosidase $\alpha$ acid- $G A A^{64}$ and protein kinase AMP_activated non catalytic subunit $\gamma 2-P R K A G 2^{65}$ genes whereas lysosomal storage disease such as Anderson-Fabry disease and Danon disease are linked to mutation in galactosidase $\alpha-G L A^{66}$ and lysosomal associated membrane protein 2-LAMP ${ }^{67}$ genes respectively.

Mitochondrial disorders caused by mutations in both nuclear and mtDNA cover a broad clinical and genetic spectrum. Friedrich's ataxia for instance is caused by the expansion of intronic trinucleotide GAA repeat in the mitochondrial frataxin- $F X N$ gene ${ }^{68}$ and inheritance is complex due to unequal proportion of abnormal mitochondria received from the mother, but also due to an unequal segregation of mitochondria during development.

Table 4. Cardiomyopathies and ion channel diseases.

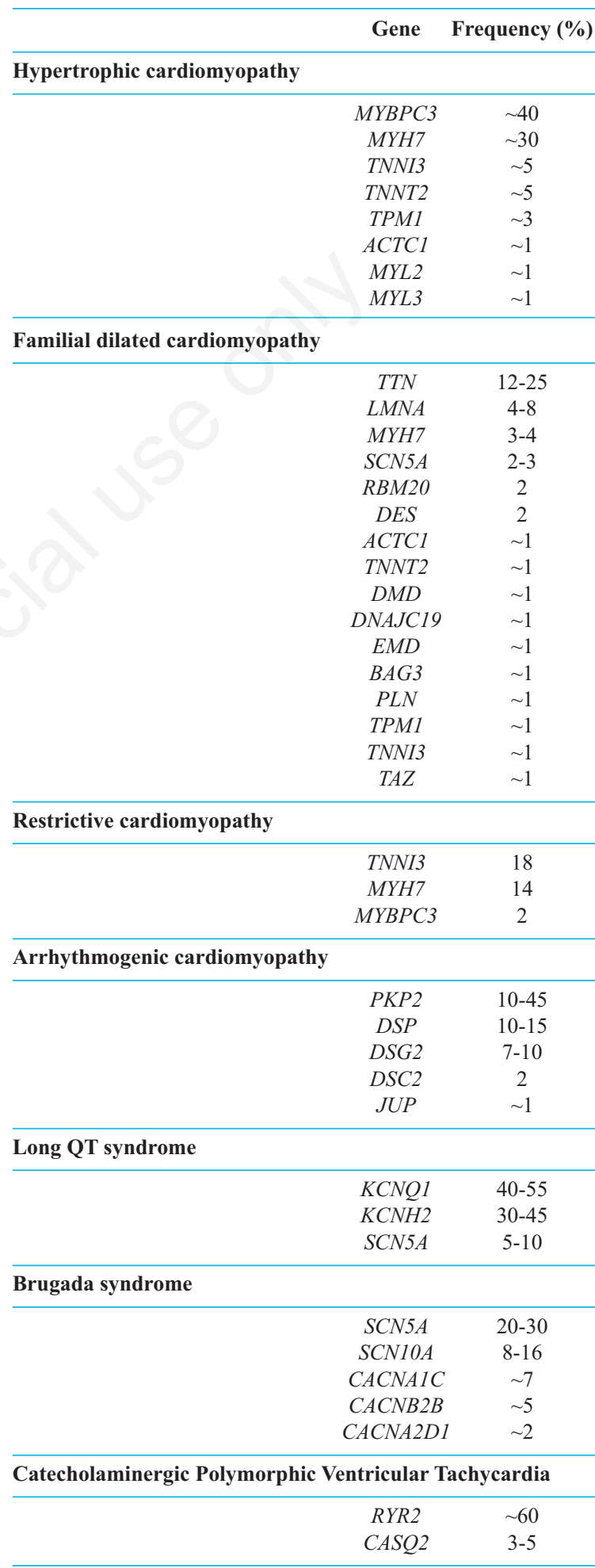


RASopathies including Noonan syndrome and Costello syndrome, are developmental syndromes caused by mutations in genes involved in the RASMAPK pathway (PTPN11, RAF1, SOS1, KRAS, NRAS, BRAF, HRAS). ${ }^{69-71}$ These conditions share many phenotypic features including dysmorphic facies, cardiac abnormalities, cognitive impairment and a predisposition to malignancy. Neuromuscular disorders represent another important group of diseases associated with HCM. Genes heavily expressed in the heart, such as DES, CRYAB and FHL1, have been associated with coexisting skeletal and cardiac myopathies. ${ }^{72-74}$

Dilated cardiomyopathy (DCM) is a myocardial disorder characterized by increased LV chamber size and systolic dysfunction, in the absence of abnormal loading conditions or coronary artery disease. ${ }^{75,76}$ DCM is more common in men than in women, with an overall prevalence of 1:2500 and a conservative annual incidence of 7 per 10,000. ${ }^{77}$ The etiologies of DCM span from inherited pathogenic gene mutations to acquired toxic and metabolic insults and chronic myocarditis. A genetic background has been identified in $\sim 40 \%$ of familial forms and more rarely in sporadic forms. ${ }^{78}$ Acquired forms (i.e. toxic, peripartum and tachycardia-induced cardiomyopathy) may also exhibit a genetic predisposition.

Systolic dysfunction is the hallmark pathophysiologic feature of DCM. Reduced sarcomere contractility can increase ventricular volumes to maintain cardiac output through the Frank-Starling mechanism, producing the thin-walled LV appearance that is observed in overt DCM. ${ }^{79}$ Diagnostic criteria have been proposed to encompass a broad spectrum of genetic and acquired disorders that manifest with electrical and functional abnormalities that change over time.

DCM appears to be inherited as a monogenic trait with autosomal dominant, autosomal recessive, Xlinked and matrilineal modes. More than 50 genes have been related to the disease pathogenesis of familial forms (Table 4). ${ }^{80}$ Since the identification of the first mutation in the actin $\alpha$ cardiac muscle 1-ACTC1 gene associated with familial DCM, ${ }^{61}$ various genes encoding for proteins acting at different levels in the cardiomyocyte have been implicated in DCM, e.g. sarcomere, cytoskeleton, ion channels, nucleus and intercalated disc complexes. About $13 \%$ of patients carry at least 2 mutations in the same gene (compound heterozygosis) or in different genes (digenic heterozygosis), related to a worse prognosis. ${ }^{80}$

Titin-TTN truncating mutations have been linked to DCM, accounting for $19-25 \%$ of familial forms and $11-18 \%$ of sporadic forms ${ }^{81}$ However, TTN truncating mutations can be also found in $2-3 \%$ of healthy population, ${ }^{82}$ making definition of mutations as pathogenic challenging. TTN missense mutations, with only few exceptions, are currently considered benign. ${ }^{83,84}$ Lamin A/C (LMNA) mutations are found in up to 8\% of DCM patients characterized by early onset (between 30 and 40 years) and conduction defects, atrial fibrillation, left bundle branch block, major ventricular arrhythmias and SCD, even in the absence of systolic left ventricular (LV) dysfunction..$^{85-87}$ Among sarcomeric genes causing DCM, 4-8\% of DCM patients carry mutations in myosin protein such as MYH7 and another $2 \%$ in troponin T-TNNT2.

Restrictive cardiomyopathies (RCMs) are currently classified according to their etiology as either primary (idiopathic RCM) or secondary (infiltrative such as amyloidosis or storage diseases) ${ }^{88,89}$ Indeed, cardiac amyloidosis resulting from extracellular deposition of amyloid fibrils either from misfolded immunoglobulin light chain or from transthyretin-TTR protein, is an increasingly recognized cause of heart failure with preserved ejection fraction, and should be considered in the differential diagnosis of RCM patients. Idiopathic RCM is the least common of all cardiomyopathies, characterized by normal LV chamber size and wall thickness but increased wall stiffness, diffuse fibrosis, myocyte hypertrophy and progressive atrial enlargement. ${ }^{90}$ In the largest series of RCM cases reported thus far, the mean age at diagnosis was 64 years (range 10 to 90 years) in the absence of infiltrative disease, long-standing untreated hypertension or other cardiac conditions known to impair diastolic ventricular filling. ${ }^{91}$ The risk of death is higher for males with left atrial dimension $>60 \mathrm{~mm}$, age $>70$ years and higher New York Heart Association (NYHA) function class. RCM in adults has a prolonged course of disease as compared to pediatric cases which have often shown poor prognosis with high mortality rate. ${ }^{91}$ Familial disease as well as sporadic cases have been described.

Heart failure due to diastolic dysfunction is the most common initial manifestation with a wide range of symptoms such as diminished exercise tolerance, dyspnea, edema, and palpitation. Increased myofilament sensitivity to calcium, marked deposition of collagen type III or of desmin have all been implicated in the pathogenesis of this condition. ${ }^{92}$

Familial RCM is characterized by autosomal dominant inheritance with variable expressivity ranging from skeletal myopathy, particularly affecting distal muscles of the extremities, to atrioventricular block ${ }^{88,89}$ Cardiac troponin I-TNNI3 was the first gene associated with RCM, ${ }^{93}$ and since then missense mutations have been identified in $18 \%$ of young patients with marked myofibrillar disarray in the absence of LVH. Up to $14 \%$ of RCM patients carry a mutation in $\beta$ myosin heavy chain- $M Y H 7$ and exhibit a mixed phenotype with HCM, more dyspnea, lower exercise capacity and higher rate of mortality, cardiac 
transplantation or implantable cardioverter-defibrillator discharges. ${ }^{94}$ Mutations in other sarcomeric (TNNT2, MYBPC3, MYL2, MYL3 and ACTC $)^{95-97}$ and non-sarcomeric genes (MYPN, TTN, FLNC, CRYAB and $D E S)^{98-101}$ accounting for less than $2 \%$ of cases have also been described in RCM (Table 4).

Arrhythmogenic cardiomyopathy (AC) is a rare disease of the heart muscle pathologically characterized by fibrofatty myocardial replacement and, clinically, by prominent ventricular arrhythmias. ${ }^{102-105}$ The estimated prevalence of $\mathrm{AC}$ in the general population ranges from 1:2000 to 1:5000. ${ }^{104-106} \mathrm{AC}$ affects more frequently males than females (up to $3: 1$ ). It becomes clinically overt most often in the second to fourth decade of life. ${ }^{104-106}$

The hallmark lesion of $\mathrm{AC}$ is the replacement of the ventricular myocardium by fibrofatty tissue. ${ }^{102,103,107}$ In AC myocardial atrophy is a genetically determined process that occurs progressively with time, it starts from the epicardium and extends toward the endocardium to become transmural, resulting into progressive wall thinning. It typically displays right ventricular aneurysms located in the so-called triangle of dysplasia (i.e. inflow, apex and outflow tracts). ${ }^{107}$ Biventricular and left-dominant disease variants have been identified extending the spectrum of AC phenotypic expressions that affects both ventricles. ${ }^{105}$ The phenotypic expression of AC varies considerably, ranging from the clinical profiles of asymptomatic family members with concealed structural abnormalities and no arrhythmias to symptomatic patients experiencing arrhythmic cardiac arrest or undergoing cardiac transplantation because of refractory heart failure. ${ }^{104,108-113} 1994$ and 2010 task force criteria were developed to diagnose the original right-dominant disease phenotype but did not consider specific criteria for detecting LV involvement and the more recently recognized left-sided phenotypic variants. ${ }^{114}$

$\mathrm{AC}$ exhibits an autosomal dominant mode of inheritance even though, recessive forms with and without cutaneous abnormalities have been reported. ${ }^{115}$ Heterozygous or compound mutations in genes encoding proteins of desmosomes have been identified in $50 \%$ of cases. ${ }^{115}$ Other genetic (non-desmosomal) and non-genetic causes of the disease have been also postulated. The first mutation, a deletion in plakoglobin$J U P$, was identified in a recessive form of $\mathrm{AC},{ }^{116}$ followed few years later by the identification of mutation in desmoplakin-DSP in the autosomal recessive and dominant forms. ${ }^{117}$ Since then, disease-causing mutations are detected in genes encoding mainly for desmosomal proteins (Table 4). The most common mutant gene is plakophilin 2-PKP2 (10-45\%), followed by $D S P(10-15 \%)$, desmoglein 2-DSG2 (7$10 \%$ ), and desmocollin 2-DSC2 (2\%). ${ }^{118-121}$ Copy number variations (CNVs) of desmosomal genes have also been linked to AC substantially increasing the diagnostic yield of genetic testing. ${ }^{122}$ Screening for nondesmosomal genes marginally increases the rate of detection of gene mutations, despite the fact that some mutations in specific genes such as transmembrane protein 43-TMEM43 p.S358L and phospholamban$P L N$ p.R14del can be highly prevalent in certain populations due to a founder effect. ${ }^{123,124}$ Compound /digenic heterozygosity has been identified in up to $25 \%$ of patients accounting for both phenotypic variability and more malignant life-time arrhythmic outcome (dose-effect). ${ }^{125}$

\section{Ion channel diseases}

Long QT syndrome (LQT) is a cardiac electro-physiologic disorder, characterized by QT prolongation and T-wave abnormalities at the electrocardiogram (ECG), which affects repolarization of the heart. The arrhythmic events occur due to runs of torsades de pointes ventricular tachycardia, which, according to its duration, produces syncope and deteriorates into ventricular fibrillation leading to cardiac arrest and SCD. Patients affected by LQTs have been identified all over the world except for black Africans and African-Americans. Among Caucasians, the prevalence of LQTs has been estimated as 1:2000 in apparently healthy live births with a 14 years mean age of presentation. ${ }^{126}$

Prolongation of the QT interval is the hallmark of LQTs even though it is not always present. Ventricular repolarization is not only prolonged but often shows bizarre morphologic alterations, some of which tend to be gene-specific. The diagnosis of LQTs is mainly based on the measurement of the corrected QT (QTc). A prolonged QTc $>460 \mathrm{~ms}$ is sufficient to make a diagnosis of LQTs, in the absence of secondary causes of QTc prolongation that can occur with drugs, acquired cardiac conditions, electrolyte imbalance, and unbalanced diets. A scoring system has been established, which takes into account the age of the patient, medical and family history, symptoms, and QTc and provides a probability of the diagnosis of LQTs. ${ }^{127}$ To date 15 subtypes of LQTs have been described which may be grouped into categories based on the mode of inheritance and extracardiac manifestations: RomanoWard syndrome ${ }^{128,129}$ (LQT 1-6, LQT 9-13) is characterized by an isolated prolonged QT interval and comprises the 3 major clinical phenotypes (LQT type 1,2 and 3) associated with specific triggers of cardiac events: exercise/emotion (LQT1), auditory stimuli (LQT2) and sleep (LQT3).

All syndromes with an extracardiac manifestation are characterized by an extremely prolonged QT interval; Andersen-Tawil syndrome (LQT7) ${ }^{130}$ and Timothy syndrome (LQT8) ${ }^{131}$ exhibit an autosomal dominant inheritance and facial dysmorphism whereas 
the Jervell and Lange-Nielsen syndrome ${ }^{132}$ is characterized by congenital deafness and an autosomal recessive inheritance.

Mutations in more than 15 genes have been associated with LQTs, most encoding for subunits of potassium, sodium and calcium voltage-dependent ion channels (Table 4). Genetic screening identifies a disease-causing mutation in $75 \%$ of LQTs although $20 \%$ $25 \%$ of the patients with LQTs confirmed by the presence of an LQTs gene mutation may have a normal range QTc. ${ }^{133}$ Three main genes, KCNQ1 ${ }^{134}$ $K C N H 2,135$ and $S C N 5 A,{ }^{136}$ account for $90 \%$ of positively genotyped LQT cases. ${ }^{137}$ Gene specific therapy does exist underlying a major role for genetic testing in affected patients unlike other inherited CVD.

Short QT syndrome (SQT) is an extremely rare inherited cardiac channelopathy characterized by an accelerated cardiac repolarization, responsible for the development of life-threatening arrhythmias. Global population prevalence is difficult to establish due to the limited number of cases ( $<200$ cases) identified worldwide. Fatal arrhythmias in early phase of SQTs are common, thus SQT frequency and lethality in adults is underestimated. ${ }^{138}$

Patients with SQT show a characteristic reduced adaptation of the QT interval to changes in heart rate. The alterations of the gating properties of the $\mathrm{K}^{+}$channels caused by SQT-related variants result in an increased efflux of $\mathrm{K}^{+}$during the plateau phase. This globally accelerates the cardiac repolarization and results in a remarkable and homogeneous shortening of the ventricular action potential duration, which represents the mechanism underlying arrhythmic susceptibility and SCD risk.

SQT displays an autosomal dominant pattern of inheritance with high phenotype penetrance. ${ }^{139}$ SQT is associated with gain-of-function alterations in genes encoding outward $\mathrm{K}+$ channels $(\mathrm{KCNH} 2, \mathrm{KCNQ1}$ and $K C N J 2)^{140-142}$ and loss-of-function mutations in genes encoding different subunits of cardiac L-type $\mathrm{Ca}^{+}$ channel (CACNA1C and CACNB2). ${ }^{143}$ Recently 3 different mutations have been identified in SQT patients in genes encoding ion channels and plasma membrane proteins (CACN2D1, SCN5A and SLC4A3), ${ }^{143-145}$ however no conclusive data exist concerning the association with SQT. The overall yield of genetic testing is low (range 15-30\%), with none of the identified genes affecting more than $5 \%$ of the known SQT population. ${ }^{138}$

Brugada syndrome $(\mathrm{BrS})$ is an inherited disease characterized by a coved-type ST-segment elevation in the right precordial ECG leads and increased risk of SCD, in the absence of structural abnormalities. ${ }^{146,147}$ The cornerstone of BrS definition is its characteristic ECG pattern that can be present spontaneously or unmasked by drugs. BrS estimated prevalence is about 1:10,000-25,000 worldwide with much higher incidence in Asian and Southeast Asian countries, especially Thailand, the Philippines, and Japan, reaching $0.5-1$ per $1000 .{ }^{148,149} \mathrm{BrS}$ is $8-10$ times more prevalent in men than in women. ${ }^{150}$

$\mathrm{BrS}$ is diagnosed in patients with ST-segment elevation with type 1 morphology $\geq 2 \mathrm{~mm}$ in $\geq 1$ lead in the right precordial leads $\mathrm{V} 1, \mathrm{~V} 2$, positioned in the $2^{\text {nd }}$, $3^{\text {rd }}$, or $4^{\text {th }}$ intercostal space. This occurs either spontaneously or after a provocative drug test with intravenous administration of class I antiarrhythmic drugs (sodium channel blocking agents: ajmaline, flecainide, pilsicainide, or procainamide). Patients with a spontaneous type I ECG at baseline (without conditions known to unmask the signature sign, i.e., drugs and fever) have high risk of cardiac arrhythmic events at follow-up. ${ }^{150}$

Inheritance of BrS occurs via an autosomal dominant mode of transmission. Since the identification of the first loss-of-function mutation in SCN5A $A^{151} 17$ more genes (Table 4) have been linked to the disease with anecdotal frequencies. In all 18 genotypes, either a decrease in the inward sodium or calcium current or an increase in one of the outward potassium currents has been shown to be associated with the BrS phenotype. To date, more than 500 loss-of-function mutations in the $S C N 5 \mathrm{~A}$ gene are known to cause $\mathrm{BrS}$, accounting for $20 \%$ to $30 \%$ of $\mathrm{BrS}$ patients. The vast majority are single nucleotide substitutions (missense) or small insertion/deletions. These mutations alter the structure of ion channels made with the SCN5A protein and disrupt the flow of sodium ions into cardiac muscle cells. Other mutations prevent the $S C N 5 A$ gene from producing any functional ion channels, which also reduces the inward flow of sodium ions. ${ }^{152,153}$

Progressive cardiac conduction defect (PCCD), also known as Lenègre disease, ${ }^{154}$ is characterized by the progressive slowing of conduction velocity through the His-Purkinje system usually in older individuals.

PCCD is clinically characterized by a prolonged $\mathrm{P}$-wave duration, $\mathrm{PR}$ interval, and QRS widening with axis deviation on the surface ECG. The diagnosis is based on clinical data together with family history and 12-lead ECG, nevertheless congenital heart disease or cardiomyopathies should be investigated. Indeed, the majority of cases present normal cardiac structure and contractile function, but complete atrio-ventricular block may lead to LV dilatation and heart failure.

PCCD exhibits an autosomal dominant trait with incomplete penetrance and variable expressivity. Mutations in SCN5A, TRPM4, SCN1B, GJA5 ${ }^{155,156}$ genes have been identified in patients with familial PCCD, presenting a structural normal heart, with only subtle fibrosis. Instead, in the presence of concomitant congenital heart defects, mutations have been localized in 
early cardiac transcription factor such as $N K X 2.5$ GATA4 or TBX5. ${ }^{157,158}$ Mutations in LMNA have also been reported in patients affected by severe PCCD without skeletal muscle involvement and dilated LV. ${ }^{159}$

Catecholaminergic polymorphic ventricular tachycardia (CPVT) is a rare inheritable arrhythmogenic disorder characterized by adrenergic-induced bidirectional and polymorphic ventricular tachycardia. The estimated prevalence of the disease is about 1:10,000 but a systematic study population is lacking. ${ }^{125}$

Clinical manifestations often occur in the first or second decade of life and usually triggered by physical activity or emotional stress. ${ }^{160} \mathrm{CPVT}$ patients present a normal basal ECG and Echo making diagnosis challenging. Indeed fainting episode may be attributed to neurologic disorder. Family history of exercise-related syncope, and SCD are reported in 30\% of cases and may help directing the diagnosis. The first-line therapeutic preference for patients is beta-blockers without intrinsic sympathomimetic activity, and exercise restriction. Flecainide might be considered in case of $\beta$ blockers inefficacy, ${ }^{161,162}$ as well as left cardiac sympathetic denervation in beta-blockers intolerant patients. ${ }^{163,164}$

CPVT is manly inherited as an autosomal dominant trait caused by mutations in the ryanodine receptor- $R Y R 2,{ }^{165-167}$ however also a recessive form has been identified linked to mutation in the cardiac calsequestrin-CASQ2. ${ }^{168}$ A causative mutation is identified in almost $60 \%$ of patients suggesting the presence of other factors involved in the disease pathogenesis. Recently, mutations in other genes $K C N J 2, A N K 2, T R D N$ and $C A L M 1$ have been reported in patients with clinical features resembling CPVT but their role is still under investigation. ${ }^{169-173}$

\section{Congenital heart disease}

Congenital heart diseases are characterized by structural abnormality of the heart and great vessels that is present at birth. ${ }^{174,175} \mathrm{CHD}$ are considered multifactorial in origin, including genetic and non-genetic acquired risk factors. Genetic testing for CHD is increasingly becoming part of standard care. Phenotyping and family history should strongly guide the type of testing suggested.

Familial CHD mutations may occur as autosomal dominant, recessive, or X-linked traits and are characterized by high penetrance associated with variable clinical manifestations. Aneuploidies were the earliest identified genetic causes of CHD, observed in $35 \%$ to $50 \%$ of live born children with trisomy $21,60 \%$ to $80 \%$ of live born children with trisomy 13 and trisomy 18 , and $33 \%$ with monosomy X. ${ }^{176}$

Syndromic CHD have been demonstrated to be caused by several well-characterized large CNVs such as the $3 \mathrm{Mb}$ deletion del22q11 characterized by a variable phenotype encompassing palate abnormalities, hypocalcemia, immunodeficiency, characteristic facial features, and neurodevelopmental abnormalities including learning disabilities and psychiatric disorders, also known as DiGeorge syndrome and velo-cardiofacial syndrome. ${ }^{177-179}$ Other CHD-associated CNVs are the deletion del8p23, which includes the cardiac transcription factor GATA4 characterized by developmental delay; the deletion del7q11 causing haploinsufficiency for elastin and William syndrome, ${ }^{180,181}$ and the deletion del11q24-25 resulting in Jacobsen syndrome. ${ }^{182,183}$ Besides syndromes associated with $\mathrm{CNVs}$, their global contribution to CHD has been investigated in several large cohorts of patients with CHD such as, tetralogy of Fallot, ${ }^{184}$ heterotaxy, ${ }^{185}$ and hypoplastic left heart, ${ }^{186-188}$ all of which show an overrepresentation of rare CNVs, and de novo CNVs compared with controls. ${ }^{189}$

Approximately $2 \%$ of $\mathrm{CHD}$ is due to inherited point mutations and many of the genes first implicated in inherited CHD are members of a core group of cardiac transcription factors that includes NKX2.5, the GATA family of zinc-finger proteins, T-box factors including TBX5 and TBX1 and MEF2 factors. ${ }^{190-192}$

The explosion of NGS enlarges the understanding of CHD complex genetics, allowing the identification of mutations that were undefinable through traditional genomic methods, such as de novo. De novo mutations account for approximately $10 \%$ of CHD and, in general, are more deleterious and cause more significant comorbidities than the mutations seen in Mendelian CHD. ${ }^{193}$ Mosaic de novo variants have been shown to contribute up to $20 \%$ of sporadic cases in several developmental disorders, including Sturge-Weber syndrome, ${ }^{194}$ facioscapulohumeral muscular dystrophy, ${ }^{195}$ and segmental neurofibromatosis. ${ }^{196}$ There have also been clinical reports suggesting pathogenic mosaic CNVs in patients with CHD. ${ }^{197}$ Finally, detection limitations of CNVs and single-nucleotide variants may lead to underestimation of their contribution in some CHDs which are likely to be the result of multi-locus inheritance, or caused by mutations in noncoding DNA.

\section{Genetic testing in cardiovascular diseases and the need of multidisciplinary cardio-genetic referral centers}

NGS-based platforms for identifying causative variants increased significantly the success rate of genetic testing. Indeed, the yield of genetic testing is variable across CVDs, ranging from a very low value of $2-5 \%$ in valvular heart disease up to $75 \%$ in LQT syndrome. On the other hand, NGS increased also the difficulty in genetic variants interpretation, since the analysis of large numbers of genes may lead to the 


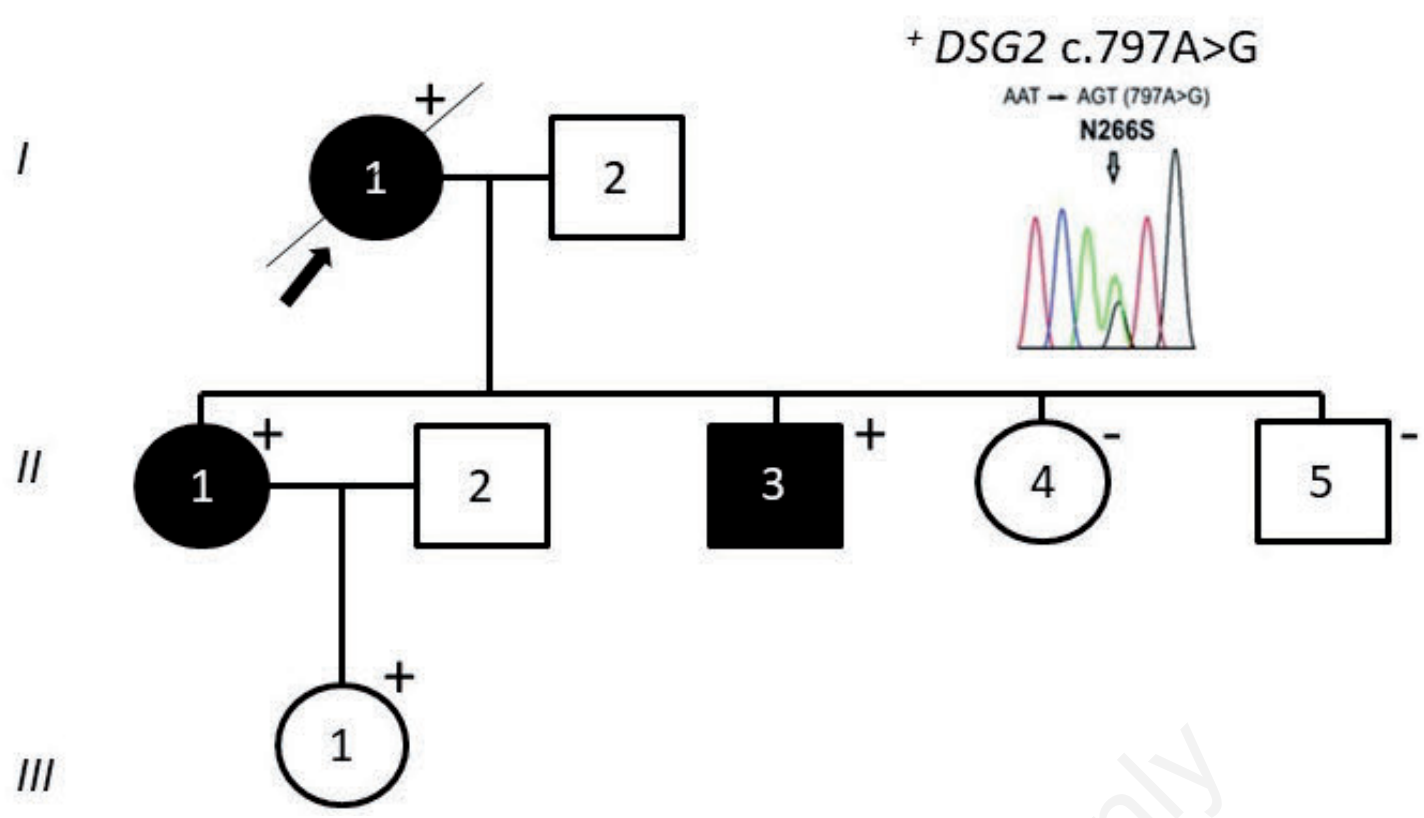

Figure 1. Family pedigree with a missense mutation in Desmoglein-2 gene and autosomal dominant inheritance of the arrhythmogenic cardiomyopathy. Black and white symbols represent affected and unaffected individuals, respectively, Presense (+) or absence (-) of the DSG2 mutation is indicated and arrow highlights the proband. Modified from Pilichou et al., 2006. ${ }^{120}$

identification of a large number of sequence variants with uncertain clinical significance (VUS). Thus, a VUS in a gene known to cause disease can create significant clinical equipoise regarding its use in predictive testing and diagnosis. As such, genetic testing and its interpretation should be performed by genetic counselors in dedicated cardio-genetic centers, with pre- and post-counseling facilities. Characterizing the underlying genetic cause of these cases reassures the patient, directs family screening and fertility planning, and in selected cases can guide therapy. ${ }^{1}$ For example, identifying the causal gene in LQT allows target therapy in subsets of disease caused by potassium versus sodium channel dysfunction. Further, clarifying that is due to variants in TTR or Fabry's disease can allow targeted therapies including RNA silencing, isoform stabilizers and enzyme replacement.

\section{Conclusions}

Genetic testing can be used in a clinically affected patient to confirm diagnosis, or to formulate a differential diagnosis among overlapping phenotypes or between hereditary and acquired (nongenetic) forms of CVD. Moreover, after the identification of a pathogenic mutation in the proband, cascade genetic screening is recommended in clinically unaffected relatives, to identify asymptomatic carriers for early diagnosis and preventive strategies (Figure 1). Finally, a precise molecular diagnosis can help risk stratification in specific diseases and may guide management such as in LQT syndrome. Many knowledge gaps still exist in our understanding of CVDs. Establishing clear genotypephenotype correlations remains a challenge, as the presently known heritable factors only partially explain the multiple cardiovascular phenotypes.

However, precision medicine is becoming increasingly possible with integration of the genome into the medical record and high throughput sequencing platforms for gene expression. The potential role of modifier genes, environmental and epigenetic factors in disease onset, progression and variable phenotype may soon unravel novel pathogenetic mechanisms.

\section{References}

1. Girolami F, Frisso G, Benelli M, et al. Contemporary genetic testing in inherited cardiac disease: tools, ethical issues, and clinical applications. J Cardiovasc Med (Hagerstown) 2018;19:1-11.

2. Khera AV, Emdin CA, Drake I, et al. Genetic risk, adherence to a healthy lifestyle, and coronary disease. N Engl J Med 2016;375:2349-58.

3. Gertler MM, Garn SM, White PD. Young candidates for coronary heart disease. J Am Med Assoc 1951;147: 621-5.

4. Erdmann J, Grosshennig A, Braund PS, et al. New susceptibility locus for coronary artery disease on chromosome 3q22.3. Nat Genet 2009;41:280-2.

5. Consortium CAD, Deloukas P, Kanoni S, et al. Large- 
scale association analysis identifies new risk loci for coronary artery disease. Nat Genet 2013;45:25-33.

6. Nikpay M, Goel A, Won HH, et al. A comprehensive 1,000 Genomes-based genome-wide association metaanalysis of coronary artery disease. Nat Genet 2015;47: 1121-30.

7. Akioyamen LE, Genest J, Shan SD, et al. Estimating the prevalence of heterozygous familial hypercholesterolaemia: a systematic review and meta-analysis. BMJ Open 2017;7:e016461.

8. Cuchel M, Bruckert E, Ginsberg HN, et al. Homozygous familial hypercholesterolaemia: new insights and guidance for clinicians to improve detection and clinical management. A position paper from the Consensus Panel on Familial Hypercholesterolaemia of the European Atherosclerosis Society. Eur Heart J 2014;35: 2146-57.

9. Nordestgaard BG, Chapman MJ, Humphries SE, et al. Familial hypercholesterolaemia is underdiagnosed and undertreated in the general population: guidance for clinicians to prevent coronary heart disease: consensus statement of the European Atherosclerosis Society. Eur Heart J 2013;34:3478-90a.

10. Defesche JC, Gidding SS, Harada-Shiba M, et al. Familial hypercholesterolaemia. Nat Rev Dis Primers 2017;3:17093.

11. Dron JS, Hegele RA. Complexity of mechanisms among human proprotein convertase subtilisin-kexin type 9 variants. Curr Opin Lipidol 2017;28:161-9.

12. Paquette M, Genest J, Baass A. Familial hypercholesterolemia: experience from the French-Canadian population. Curr Opin Lipidol 2018;29:59-64.

13. Go AS, Mozaffarian D, Roger VL, et al. Heart disease and stroke statistics-2013 update: a report from the American Heart Association. Circulation 2013;127:e6e245.

14. Basso C, Boschello M, Perrone C, et al. An echocardiographic survey of primary school children for bicuspid aortic valve. Am J Cardiol. 2004;93:661-3.

15. Garg V, Muth AN, Ransom JF, et al. Mutations in NOTCH1 cause aortic valve disease. Nature 2005;437: 270-4.

16. Cecconi M, Nistri S, Quarti A, et al. Aortic dilatation in patients with bicuspid aortic valve. J Cardiovasc Med (Hagerstown) 2006;7:11-20.

17. Della Corte A, Bancone C, Buonocore M, et al. Pattern of ascending aortic dimensions predicts the growth rate of the aorta in patients with bicuspid aortic valve. JACC Cardiovasc Imaging 2013;6:1301-10.

18. Masri A, Kalahasti V, Alkharabsheh S, et al. Characteristics and long-term outcomes of contemporary patients with bicuspid aortic valves. J Thorac Cardiovasc Surg 2016;151:1650-9e1.

19. Mohamed SA, Aherrahrou Z, Liptau H, et al. Novel missense mutations (p.T596M and p.P1797H) in NOTCH1 in patients with bicuspid aortic valve. Biochem Biophys Res Commun 2006;345:1460-5.

20. McKellar SH, Tester DJ, Yagubyan M, et al. Novel NOTCH1 mutations in patients with bicuspid aortic valve disease and thoracic aortic aneurysms. J Thorac Cardiovasc Surg 2007;134:290-6.

21. Foffa I, Ait Ali L, Panesi P, et al. Sequencing of NOTCH1, GATA5, TGFBR1 and TGFBR2 genes in fa- milial cases of bicuspid aortic valve. BMC Med Genet 2013;14:44.

22. Padang R, Bagnall RD, Richmond DR, et al. Rare nonsynonymous variations in the transcriptional activation domains of GATA5 in bicuspid aortic valve disease. J Mol Cell Cardiol 2012;53:277-81.

23. Bonachea EM, Chang SW, Zender G, et al. Rare GATA5 sequence variants identified in individuals with bicuspid aortic valve. Pediatr Res 2014;76:211-6.

24. Shi LM, Tao JW, Qiu XB, et al. GATA5 loss-of-function mutations associated with congenital bicuspid aortic valve. Int J Mol Med 2014;33:1219-26.

25. Yang B, Zhou W, Jiao J, et al. Protein-altering and regulatory genetic variants near GATA4 implicated in bicuspid aortic valve. Nat Commun 2017;8:15481.

26. Mohamed SA, Hanke T, Schlueter C, et al. Ubiquitin fusion degradation 1-like gene dysregulation in bicuspid aortic valve. J Thorac Cardiovasc Surg 2005;130: 1531-6.

27. Wooten EC, Iyer LK, Montefusco MC, et al. Application of gene network analysis techniques identifies AXIN1/PDIA2 and endoglin haplotypes associated with bicuspid aortic valve. PLoS One 2010;5:e8830.

28. Micale L, Turturo MG, Fusco C, et al. Identification and characterization of seven novel mutations of elastin gene in a cohort of patients affected by supravalvular aortic stenosis. Eur J Hum Genet 2010;18:317-23.

29. Delling FN, Vasan RS. Epidemiology and pathophysiology of mitral valve prolapse: new insights into disease progression, genetics, and molecular basis. Circulation 2014;129:2158-70.

30. Lardeux A, Kyndt F, Lecointe S, et al. Filamin-a-related myxomatous mitral valve dystrophy: genetic, echocardiographic and functional aspects. J Cardiovasc Transl Res 2011;4:748-56.

31. Kyndt F, Gueffet JP, Probst V, et al. Mutations in the gene encoding filamin A as a cause for familial cardiac valvular dystrophy. Circulation 2007;115:40-9.

32. Thiene G, Basso C. Filamin A mitral valve disease: prolapse, dystrophy, or dysplasia? Eur Heart J 2018;39: 1278-80.

33. Kern CB, Wessels A, McGarity J, et al. Reduced versican cleavage due to Adamts9 haploinsufficiency is associated with cardiac and aortic anomalies. Matrix Biol 2010;29:304-16.

34. Saratzis A, Abbas AA, Kiskinis D, et al. Abdominal aortic aneurysm: a review of the genetic basis. Angiology 2011;62:18-32.

35. Clouse WD, Hallett JW, Jr., Schaff HV, et al. Improved prognosis of thoracic aortic aneurysms: a populationbased study. JAMA 1998;280:1926-9.

36. Albornoz G, Coady MA, Roberts M, et al. Familial thoracic aortic aneurysms and dissections-incidence, modes of inheritance, and phenotypic patterns. Ann Thorac Surg 2006;82:1400-5.

37. Dietz HC, Pyeritz RE, Hall BD, et al. The Marfan syndrome locus: confirmation of assignment to chromosome 15 and identification of tightly linked markers at 15q15-q21.3. Genomics 1991;9:355-61.

38. Dietz HC, Cutting GR, Pyeritz RE, et al. Marfan syndrome caused by a recurrent de novo missense mutation in the fibrillin gene. Nature 1991;352:337-9.

39. Verstraeten A, Alaerts M, Van Laer L, et al. Marfan syn- 
drome and related disorders: 25 years of gene discovery. Hum Mutat 2016;37:524-31.

40. Cury M, Zeidan F, Lobato AC. Aortic disease in the young: genetic aneurysm syndromes, connective tissue disorders, and familial aortic aneurysms and dissections. Int J Vasc Med 2013;2013:267215.

41. Loeys BL, Schwarze U, Holm T, et al. Aneurysm syndromes caused by mutations in the TGF-beta receptor. N Engl J Med 2006;355:788-98.

42. Kuzmik GA, Sang AX, Elefteriades JA. Natural history of thoracic aortic aneurysms. J Vasc Surg 2012; 56:565-71.

43. MacCarrick G, Black JH, 3rd, Bowdin S, et al. LoeysDietz syndrome: a primer for diagnosis and management. Genet Med 2014;16:576-87.

44. Pepin M, Schwarze U, Superti-Furga A, et al. Clinical and genetic features of Ehlers-Danlos syndrome type IV, the vascular type. N Engl J Med 2000;342:673-80.

45. Rea G, Stewart FJ. Genetic biomarkers in aortopathy. Biomark Med 2013;7:547-63.

46. Oderich GS, Panneton JM, Bower TC, et al. The spectrum, management and clinical outcome of Ehlers-Danlos syndrome type IV: a 30-year experience. J Vasc Surg 2005;42:98-106.

47. Goldfinger JZ, Halperin JL, Marin ML, et al. Thoracic aortic aneurysm and dissection. J Am Coll Cardiol 2014;64:1725-39.

48. Erbel R, Aboyans V, Boileau C, et al. 2014 ESC Guidelines on the diagnosis and treatment of aortic diseases: Document covering acute and chronic aortic diseases of the thoracic and abdominal aorta of the adult. The Task Force for the Diagnosis and Treatment of Aortic Diseases of the European Society of Cardiology (ESC). Eur Heart J 2014;35:2873-926.

49. Authors/Task Force m, Elliott PM, Anastasakis A, et al. 2014 ESC Guidelines on diagnosis and management of hypertrophic cardiomyopathy: the Task Force for the Diagnosis and Management of Hypertrophic Cardiomyopathy of the European Society of Cardiology (ESC). Eur Heart J 2014;35:2733-79.

50. Berberich AJ, Hegele RA. The complex molecular genetics of familial hypercholesterolaemia. Nat Rev Cardiol 2019;16:9-20.

51. Melacini P, Basso C, Angelini A, et al. Clinicopathological profiles of progressive heart failure in hypertrophic cardiomyopathy. Eur Heart J 2010;31:2111-23.

52. Garfinkel AC, Seidman JG, Seidman CE. Genetic pathogenesis of hypertrophic and dilated cardiomyopathy. Heart Fail Clin 2018;14:139-46.

53. Geisterfer-Lowrance AA, Kass S, Tanigawa G, et al. A molecular basis for familial hypertrophic cardiomyopathy: a beta cardiac myosin heavy chain gene missense mutation. Cell 1990;62:999-1006.

54. Watkins H, Conner D, Thierfelder L, et al. Mutations in the cardiac myosin binding protein- $\mathrm{C}$ gene on chromosome 11 cause familial hypertrophic cardiomyopathy. Nat Genet 1995;11:434-7.

55. Poetter K, Jiang H, Hassanzadeh S, et al. Mutations in either the essential or regulatory light chains of myosin are associated with a rare myopathy in human heart and skeletal muscle. Nat Genet 1996;13:63-9.

56. Thierfelder L, Watkins H, MacRae C, et al. Alphatropomyosin and cardiac troponin $\mathrm{T}$ mutations cause familial hypertrophic cardiomyopathy: a disease of the sarcomere. Cell 1994;77:701-12.

57. Kimura A, Harada H, Park JE, et al. Mutations in the cardiac troponin I gene associated with hypertrophic cardiomyopathy. Nat Genet 1997;16:379-82.

58. Landstrom AP, Parvatiyar MS, Pinto JR, et al. Molecular and functional characterization of novel hypertrophic cardiomyopathy susceptibility mutations in TNNC1-encoded troponin C. J Mol Cell Cardiol 2008; 45:281-8.

59. Chung WK, Kitner C, Maron BJ. Novel frameshift mutation in Troponin C (TNNC1) associated with hypertrophic cardiomyopathy and sudden death. Cardiol Young 2011;21:345-8.

60. Mogensen J, Klausen IC, Pedersen AK, et al. Alphacardiac actin is a novel disease gene in familial hypertrophic cardiomyopathy. J Clin Invest 1999;103: R39-43.

61. Olson TM, Michels VV, Thibodeau SN, et al. Actin mutations in dilated cardiomyopathy, a heritable form of heart failure. Science 1998;280:750-2.

62. Mazzarotto F, Girolami F, Boschi B, et al. Defining the diagnostic effectiveness of genes for inclusion in panels: the experience of two decades of genetic testing for hypertrophic cardiomyopathy at a single center. Genet Med 2019;21:284-292.

63. Wicks EC, Elliott PM. Genetics and metabolic cardiomyopathies. Herz 2012;37:598-610.

64. Hers HG. alpha-Glucosidase deficiency in generalized glycogenstorage disease (Pompe's disease). Biochem J 1963;86:11-6.

65. Murphy RT, Mogensen J, McGarry K, et al. Adenosine monophosphate-activated protein kinase disease mimicks hypertrophic cardiomyopathy and Wolff-Parkinson-White syndrome: natural history. J Am Coll Cardiol 2005;45:922-30.

66. Germain DP. Fabry disease. Orphanet J Rare Dis 2010; $5: 30$.

67. Nishino I, Fu J, Tanji K, et al. Primary LAMP-2 deficiency causes X-linked vacuolar cardiomyopathy and myopathy (Danon disease). Nature 2000;406:906-10.

68. Koeppen AH. Friedreich's ataxia: pathology, pathogenesis, and molecular genetics. J Neurol Sci 2011; 303:1-12.

69. Aoki Y, Niihori T, Kawame H, et al. Germline mutations in HRAS proto-oncogene cause Costello syndrome. Nat Genet 2005;37:1038-40.

70. Sarkozy A, Obregon MG, Conti E, et al. A novel PTPN11 gene mutation bridges Noonan syndrome, multiple lentigines/LEOPARD syndrome and Noonanlike/multiple giant cell lesion syndrome. Eur J Hum Genet 2004;12:1069-72.

71. Sharland M, Burch M, McKenna WM, et al. A clinical study of Noonan syndrome. Arch Dis Child 1992;67:178-83.

72. Gueneau L, Bertrand AT, Jais JP, et al. Mutations of the FHL1 gene cause Emery-Dreifuss muscular dystrophy. Am J Hum Genet 2009;85:338-53.

73. Vicart P, Dupret JM, Hazan J, et al. Human desmin gene: cDNA sequence, regional localization and exclusion of the locus in a familial desmin-related myopathy. Hum Genet 1996;98:422-9.

74. Stoeckel ME, Osborn M, Porte A, et al. An unusual fa- 
milial cardiomyopathy characterized by aberrant accumulations of desmin-type intermediate filaments. Virchows Arch A Pathol Anat Histol 1981;393:53-60.

75. Caforio AL, Pankuweit S, Arbustini E, et al. Current state of knowledge on aetiology, diagnosis, management, and therapy of myocarditis: a position statement of the European Society of Cardiology Working Group on Myocardial and Pericardial Diseases. Eur Heart J 2013;34:2636-48, 48a-48d.

76. Pinto YM, Elliott PM, Arbustini E, et al. Proposal for a revised definition of dilated cardiomyopathy, hypokinetic non-dilated cardiomyopathy, and its implications for clinical practice: a position statement of the ESC working group on myocardial and pericardial diseases. Eur Heart J 2016;37:1850-8.

77. Taylor MR, Carniel E, Mestroni L. Cardiomyopathy, familial dilated. Orphanet J Rare Dis 2006;1:27.

78. Hershberger RE, Givertz MM, Ho CY, et al; ACMG Professional Practice and Guidelines Committee. Genetic evaluation of cardiomyopathy: a clinical practice resource of the American College of Medical Genetics and Genomics (ACMG). Genet Med. 2018;20:899-909.

79. Hinson JT, Chopra A, Nafissi N, et al. Titin mutations in iPS cells define sarcomere insufficiency as a cause of dilated cardiomyopathy. Science 2015;349:982-6.

80. Haas J, Frese KS, Peil B, et al. Atlas of the clinical genetics of human dilated cardiomyopathy. Eur Heart J 2015;36:1123-35a.

81. Herman DS, Lam L, Taylor MR, et al. Truncations of titin causing dilated cardiomyopathy. N Engl J Med 2012;366:619-28.

82. Akinrinade O, Koskenvuo JW, Alastalo TP. Prevalence of titin truncating variants in general population. PLoS One 2015;10:e0145284.

83. Begay RL, Graw S, Sinagra G, et al. Role of titin missense variants in dilated cardiomyopathy. J Am Heart Assoc 2015;4.

84. Hastings R, de Villiers CP, Hooper C, et al. Combination of whole genome sequencing, linkage, and functional studies implicates a missense mutation in titin as a cause of autosomal dominant cardiomyopathy with features of left ventricular noncompaction. Circ Cardiovasc Genet 2016;9:426-35.

85. Hasselberg NE, Haland TF, Saberniak J, et al. Lamin $\mathrm{A} / \mathrm{C}$ cardiomyopathy: young onset, high penetrance, and frequent need for heart transplantation. Eur Heart J 2018;39:853-60.

86. Sinagra G, Dal Ferro M, Merlo M. Lamin A/C cardiomyopathy: cutting edge to personalized medicine. Circ Cardiovasc Genet 2017;10.

87. van Rijsingen IA, Arbustini E, Elliott PM, et al. Risk factors for malignant ventricular arrhythmias in lamin a/c mutation carriers a European cohort study. J Am Coll Cardiol 2012;59:493-500.

88. Pereira NL, Grogan M, Dec GW. Spectrum of Restrictive and Infiltrative Cardiomyopathies: Part 1 of a 2Part Series. J Am Coll Cardiol 2018;71:1130-48.

89. Pereira NL, Grogan M, Dec GW. Spectrum of restrictive and infiltrative cardiomyopathies: part 2 of a 2-part series. J Am Coll Cardiol 2018;71:1149-66.

90. Angelini A, Calzolari V, Thiene G, et al. Morphologic spectrum of primary restrictive cardiomyopathy. Am J Cardiol 1997;80:1046-50.
91. Ammash NM, Seward JB, Bailey KR, et al. Clinical profile and outcome of idiopathic restrictive cardiomyopathy. Circulation 2000;101:2490-6.

92. Yumoto F, Lu QW, Morimoto S, et al. Drastic Ca2+ sensitization of myofilament associated with a small structural change in troponin I in inherited restrictive cardiomyopathy. Biochem Biophys Res Commun 2005;338:1519-26.

93. Mogensen J, Kubo T, Duque M, et al. Idiopathic restrictive cardiomyopathy is part of the clinical expression of cardiac troponin I mutations. J Clin Invest 2003;111:209-16.

94. Ware SM, Quinn ME, Ballard ET, et al. Pediatric restrictive cardiomyopathy associated with a mutation in beta-myosin heavy chain. Clin Genet 2008;73:165-70.

95. Menon SC, Michels VV, Pellikka PA, et al. Cardiac troponin $\mathrm{T}$ mutation in familial cardiomyopathy with variable remodeling and restrictive physiology. Clin Genet 2008;74:445-54.

96. Wu W, Lu CX, Wang YN, et al. Novel phenotype-genotype correlations of restrictive cardiomyopathy with myosin-binding protein C (MYBPC3) gene mutations tested by next-generation sequencing. J Am Heart Assoc 2015;4.

97. Kaski JP, Syrris P, Burch M, et al. Idiopathic restrictive cardiomyopathy in children is caused by mutations in cardiac sarcomere protein genes. Heart 2008; 94:1478-84

98. Purevjav E, Arimura T, Augustin S, et al. Molecular basis for clinical heterogeneity in inherited cardiomyopathies due to myopalladin mutations. Hum Mol Genet 2012;21:2039-53.

99. Brodehl A, Ferrier RA, Hamilton SJ, et al. Mutations in FLNC are associated with familial restrictive cardiomyopathy. Hum Mutat 2016;37:269-79.

100. Brodehl A, Gaertner-Rommel A, Klauke B, et al. The novel alphaB-crystallin (CRYAB) mutation p.D109G causes restrictive cardiomyopathy. Hum Mutat 2017; 38:947-52.

101. Zhang J, Kumar A, Stalker HJ, et al. Clinical and molecular studies of a large family with desmin-associated restrictive cardiomyopathy. Clin Genet 2001;59: 248-56.

102. Thiene G, Nava A, Corrado D, et al. Right ventricular cardiomyopathy and sudden death in young people. $\mathrm{N}$ Engl J Med 1988;318:129-33.

103. Basso C, Thiene G, Corrado D, et al. Arrhythmogenic right ventricular cardiomyopathy. Dysplasia, dystrophy, or myocarditis? Circulation 1996;94:983-91.

104. Basso C, Corrado D, Marcus FI, et al. Arrhythmogenic right ventricular cardiomyopathy. Lancet 2009;373: 1289-300.

105. Basso C, Bauce B, Corrado D, et al. Pathophysiology of arrhythmogenic cardiomyopathy. Nat Rev Cardiol 2011;9:223-33.

106. Nava A, Bauce B, Basso C, et al. Clinical profile and long-term follow-up of 37 families with arrhythmogenic right ventricular cardiomyopathy. J Am Coll Cardiol 2000;36:2226-33.

107. Marcus FI, Fontaine GH, Guiraudon G, et al. Right ventricular dysplasia: a report of 24 adult cases. Circulation 1982;65:384-98.

108. Fontaine G, Frank R, Guiraudon G, et al. [Significance 
of intraventricular conduction disorders observed in arrhythmogenic right ventricular dysplasia]. Arch Mal Coeur Vaiss 1984;77:872-9.

109. Corrado D, Basso C, Thiene G, et al. Spectrum of clinicopathologic manifestations of arrhythmogenic right ventricular cardiomyopathy/dysplasia: a multicenter study. J Am Coll Cardiol 1997;30:1512-20.

110. Marcus FI, Zareba W, Calkins H, et al. Arrhythmogenic right ventricular cardiomyopathy/dysplasia clinical presentation and diagnostic evaluation: results from the North American Multidisciplinary Study. Heart Rhythm 2009;6:984-92.

111. Zorzi A, Rigato I, Pilichou K, et al. Phenotypic expression is a prerequisite for malignant arrhythmic events and sudden cardiac death in arrhythmogenic right ventricular cardiomyopathy. Europace 2016;18: 1086-94.

112. Protonotarios A, Anastasakis A, Panagiotakos DB, et al. Arrhythmic risk assessment in genotyped families with arrhythmogenic right ventricular cardiomyopathy. Europace 2016;18:610-6.

113. Groeneweg JA, Bhonsale A, James CA, et al. Clinical presentation, long-term follow-up, and outcomes of 1001 arrhythmogenic right ventricular dysplasia/cardiomyopathy patients and family members. Circ Cardiovasc Genet 2015;8:437-46.

114. Sen-Chowdhry S, Syrris P, Prasad SK, et al. Left-dominant arrhythmogenic cardiomyopathy: an under-recognized clinical entity. J Am Coll Cardiol 2008;52: 2175-87.

115. Pilichou K, Thiene G, Bauce B, et al. Arrhythmogenic cardiomyopathy. Orphanet J Rare Dis 2016;11:33.

116. McKoy G, Protonotarios N, Crosby A, et al. Identification of a deletion in plakoglobin in arrhythmogenic right ventricular cardiomyopathy with palmoplantar keratoderma and woolly hair (Naxos disease). Lancet 2000;355:2119-24.

117. Norgett EE, Hatsell SJ, Carvajal-Huerta L, et al. Recessive mutation in desmoplakin disrupts desmoplakin intermediate filament interactions and causes dilated cardiomyopathy, woolly hair and keratoderma. Hum Mol Genet. 2000;9:2761-6.

118. Rampazzo A, Nava A, Malacrida S, et al. Mutation in human desmoplakin domain binding to plakoglobin causes a dominant form of arrhythmogenic right ventricular cardiomyopathy. Am J Hum Genet 2002;71: 1200-6.

119. Gerull B, Heuser A, Wichter T, et al. Mutations in the desmosomal protein plakophilin-2 are common in arrhythmogenic right ventricular cardiomyopathy. Nat Genet 2004;36:1162-4.

120. Pilichou K, Nava A, Basso C, et al. Mutations in desmoglein-2 gene are associated with arrhythmogenic right ventricular cardiomyopathy. Circulation. 2006;113:1171-9.

121. Syrris P, Ward D, Evans A, et al. Arrhythmogenic right ventricular dysplasia/cardiomyopathy associated with mutations in the desmosomal gene desmocollin-2. Am J Hum Genet 2006;79:978-84.

122. Pilichou K, Lazzarini E, Rigato I, et al. Large Genomic Rearrangements of Desmosomal Genes in Italian Arrhythmogenic Cardiomyopathy Patients. Circ Arrhythm Electrophysiol. 2017;10.
123. Merner ND, Hodgkinson KA, Haywood AF, et al. Arrhythmogenic right ventricular cardiomyopathy type 5 is a fully penetrant, lethal arrhythmic disorder caused by a missense mutation in the TMEM43 gene. Am J Hum Genet 2008;82:809-21.

124. van der Zwaag PA, van Rijsingen IA, Asimaki A, et al. Phospholamban R14del mutation in patients diagnosed with dilated cardiomyopathy or arrhythmogenic right ventricular cardiomyopathy: evidence supporting the concept of arrhythmogenic cardiomyopathy. Eur J Heart Fail 2012;14:1199-207.

125. Rigato I, Bauce B, Rampazzo A, et al. Compound and digenic heterozygosity predicts lifetime arrhythmic outcome and sudden cardiac death in desmosomal gene-related arrhythmogenic right ventricular cardiomyopathy. Circ Cardiovasc Genet 2013;6:533-42.

126. Priori SG, Wilde AA, Horie M, et al. Executive summary: HRS/EHRA/APHRS expert consensus statement on the diagnosis and management of patients with inherited primary arrhythmia syndromes. Heart Rhythm 2013;10:e85-108.

127. Schwartz PJ, Crotti L, Insolia R. Long-QT syndrome: from genetics to management. Circ Arrhythm Electrophysiol 2012;5:868-77.

128. Romano C, Gemme G, Pongiglione R. [Rare Cardiac Arrythmias of the Pediatric Age. Ii. Syncopal Attacks Due to Paroxysmal Ventricular Fibrillation. (Presentation of 1st Case in Italian Pediatric Literature)]. Clin Pediatr (Bologna) 1963;45:656-83.

129. Ward OC. A new familial cardiac syndrome in children. J Ir Med Assoc 1964;54:103-6.

130. Nguyen HL, Pieper GH, Wilders R. Andersen-Tawil syndrome: clinical and molecular aspects. Int J Cardiol 2013;170:1-16.

131. Marks ML, Trippel DL, Keating MT. Long QT syndrome associated with syndactyly identified in females. Am J Cardiol 1995;76:744-5.

132. Jervell A, Lange-Nielsen F. Congenital deaf-mutism, functional heart disease with prolongation of the Q-T interval and sudden death. Am Heart J 1957;54:59-68.

133. Goldenberg I, Zareba W, Moss AJ. Long QT syndrome. Curr Probl Cardiol 2008;33:629-94.

134. Wang Q, Curran ME, Splawski I, et al. Positional cloning of a novel potassium channel gene: KVLQT1 mutations cause cardiac arrhythmias. Nat Genet 1996; 12:17-23.

135. Curran ME, Splawski I, Timothy KW, et al. A molecular basis for cardiac arrhythmia: HERG mutations cause long QT syndrome. Cell 1995;80:795-803.

136. Wang Q, Shen J, Splawski I, et al. SCN5A mutations associated with an inherited cardiac arrhythmia, long QT syndrome. Cell 1995;80:805-11.

137. Schwartz PJ, Ackerman MJ, George AL, Jr., et al. Impact of genetics on the clinical management of channelopathies. J Am Coll Cardiol 2013;62:169-80.

138. Mazzanti A, Underwood K, Nevelev D, et al. The new kids on the block of arrhythmogenic disorders: Short QT syndrome and early repolarization. J Cardiovasc Electrophysiol 2017;28:1226-36.

139. Campuzano O, Sarquella-Brugada G, Cesar S, et al. Recent advances in short QT syndrome. Front Cardiovasc Med 2018;5:149.

140. Brugada R, Hong K, Dumaine R, et al. Sudden death 
associated with short-QT syndrome linked to mutations in HERG. Circulation 2004;109:30-5.

141. Bellocq C, van Ginneken AC, Bezzina CR, et al. Mutation in the KCNQ1 gene leading to the short QT-interval syndrome. Circulation 2004;109:2394-7.

142. Priori SG, Pandit SV, Rivolta I, et al. A novel form of short QT syndrome (SQT3) is caused by a mutation in the KCNJ2 gene. Circ Res 2005;96:800-7.

143. Antzelevitch C, Pollevick GD, Cordeiro JM, et al. Loss-of-function mutations in the cardiac calcium channel underlie a new clinical entity characterized by STsegment elevation, short QT intervals, and sudden cardiac death. Circulation 2007;115:442-9.

144. Refsgaard L, Holst AG, Sadjadieh G, et al. High prevalence of genetic variants previously associated with LQT syndrome in new exome data. Eur J Hum Genet 2012;20:905-8.

145. Thorsen K, Dam VS, Kjaer-Sorensen K, et al. Loss-ofactivity-mutation in the cardiac chloride-bicarbonate exchanger AE3 causes short QT syndrome. Nat Commun 2017;8:1696.

146. Martini B, Nava A, Thiene G, et al. Ventricular fibrillation without apparent heart disease: description of six cases. Am Heart J 1989;118:1203-9.

147. Brugada P, Brugada J. Right bundle branch block, persistent ST segment elevation and sudden cardiac death: a distinct clinical and electrocardiographic syndrome. A multicenter report. J Am Coll Cardiol 1992; 20:1391-6.

148. Fowler SJ, Priori SG. Clinical spectrum of patients with a Brugada ECG. Curr Opin Cardiol 2009;24:74-81.

149. Jellins J, Milanovic M, Taitz DJ, et al. Brugada syndrome. Hong Kong Med J 2013;19:159-67.

150. Brugada J, Campuzano O, Arbelo E, et al. Present status of Brugada syndrome: JACC state-of-the-art review. J Am Coll Cardiol 2018;72:1046-59.

151. Chen Q, Kirsch GE, Zhang D, et al. Genetic basis and molecular mechanism for idiopathic ventricular fibrillation. Nature 1998;392:293-6.

152. Sarquella-Brugada G, Campuzano O, Arbelo E, et al. Brugada syndrome: clinical and genetic findings. Genet Med 2016;18:3-12.

153. Sieira J, Dendramis G, Brugada P. Pathogenesis and management of Brugada syndrome. Nat Rev Cardiol 2016;13:744-56.

154. Lenegre J. Etiology and pathology of bilateral bundle branch block in relation to complete heart block. Prog Cardiovasc Dis 1964;6:409-44.

155. Stallmeyer B, Zumhagen S, Denjoy I, et al. Mutational spectrum in the $\mathrm{Ca}(2+)$ - activated cation channel gene TRPM4 in patients with cardiac conductance disturbances. Hum Mutat 2012;33:109-17.

156. Schott JJ, Alshinawi C, Kyndt F, et al. Cardiac conduction defects associate with mutations in SCN5A. Nat Genet 1999;23:20-1.

157. Schott JJ, Benson DW, Basson CT, et al. Congenital heart disease caused by mutations in the transcription factor NKX2-5. Science 1998;281:108-11.

158. McElhinney DB, Geiger E, Blinder J, et al. NKX2.5 mutations in patients with congenital heart disease. $\mathrm{J}$ Am Coll Cardiol 2003;42:1650-5.

159. Wolf CM, Wang L, Alcalai R, et al. Lamin A/C haploinsufficiency causes dilated cardiomyopathy and apoptosis-triggered cardiac conduction system disease. J Mol Cell Cardiol 2008;44:293-303.

160. Priori SG, Napolitano C, Memmi M, et al. Clinical and molecular characterization of patients with catecholaminergic polymorphic ventricular tachycardia. Circulation 2002;106:69-74.

161. van der Werf C, Nederend I, Hofman N, et al. Familial evaluation in catecholaminergic polymorphic ventricular tachycardia: disease penetrance and expression in cardiac ryanodine receptor mutation-carrying relatives. Circ Arrhythm Electrophysiol 2012;5:748-56.

162. Watanabe H, Chopra N, Laver D, et al. Flecainide prevents catecholaminergic polymorphic ventricular tachycardia in mice and humans. Nat Med 2009;15:380-3.

163. Olde Nordkamp LR, Driessen AH, Odero A, et al. Left cardiac sympathetic denervation in the Netherlands for the treatment of inherited arrhythmia syndromes. Neth Heart J 2014;22:160-6.

164. Hofferberth SC, Cecchin F, Loberman D, et al. Left thoracoscopic sympathectomy for cardiac denervation in patients with life-threatening ventricular arrhythmias. J Thorac Cardiovasc Surg 2014;147:404-9.

165. Priori SG, Napolitano C, Tiso N, et al. Mutations in the cardiac ryanodine receptor gene (hRyR2) underlie catecholaminergic polymorphic ventricular tachycardia. Circulation 2001;103:196-200.

166. Bauce B, Rampazzo A, Basso C, et al. Screening for ryanodine receptor type 2 mutations in families with effort-induced polymorphic ventricular arrhythmias and sudden death: early diagnosis of asymptomatic carriers. J Am Coll Cardiol 2002;40:341-9.

167. Tiso N, Stephan DA, Nava A, et al. Identification of mutations in the cardiac ryanodine receptor gene in families affected with arrhythmogenic right ventricular cardiomyopathy type 2 (ARVD2). Hum Mol Genet 2001;10:189-94.

168. Lahat H, Pras E, Olender T, et al. A missense mutation in a highly conserved region of CASQ2 is associated with autosomal recessive catecholamine-induced polymorphic ventricular tachycardia in Bedouin families from Israel. Am J Hum Genet 2001;69:1378-84.

169. Vega AL, Tester DJ, Ackerman MJ, et al. Protein kinase A-dependent biophysical phenotype for V227F-KCNJ2 mutation in catecholaminergic polymorphic ventricular tachycardia. Circ Arrhythm Electrophysiol 2009;2:540-7.

170. Bhuiyan ZA, Hamdan MA, Shamsi ET, et al. A novel early onset lethal form of catecholaminergic polymorphic ventricular tachycardia maps to chromosome 7p14p22. J Cardiovasc Electrophysiol 2007;18:1060-6.

171. Mohler PJ, Splawski I, Napolitano C, et al. A cardiac arrhythmia syndrome caused by loss of ankyrin-B function. Proc Natl Acad Sci U S A 2004;101:9137-42.

172. Roux-Buisson N, Cacheux M, Fourest-Lieuvin A, et al. Absence of triadin, a protein of the calcium release complex, is responsible for cardiac arrhythmia with sudden death in human. Hum Mol Genet 2012;21: 2759-67.

173. Nyegaard M, Overgaard MT, Sondergaard MT, et al. Mutations in calmodulin cause ventricular tachycardia and sudden cardiac death. Am J Hum Genet 2012;91: 703-12.

174. Triedman JK, Newburger JW. Trends in congenital heart disease: the next decade. Circulation 2016;133: 2716-33. 
175. van der Linde D, Konings EE, Slager MA, et al. Birth prevalence of congenital heart disease worldwide: a systematic review and meta-analysis. J Am Coll Cardiol 2011;58:2241-7.

176. Hartman RJ, Rasmussen SA, Botto LD, et al. The contribution of chromosomal abnormalities to congenital heart defects: a population-based study. Pediatr Cardiol 2011;32:1147-57.

177. Jerome LA, Papaioannou VE. DiGeorge syndrome phenotype in mice mutant for the T-box gene, Tbx1. Nat Genet 2001;27:286-91.

178. Lindsay EA, Vitelli F, Su H, et al. Tbx1 haploinsufficieny in the DiGeorge syndrome region causes aortic arch defects in mice. Nature 2001;410:97-101.

179. Merscher S, Funke B, Epstein JA, et al. TBX1 is responsible for cardiovascular defects in velo-cardio-facial/DiGeorge syndrome. Cell 2001;104:619-29.

180. Nickerson E, Greenberg F, Keating MT, et al. Deletions of the elastin gene at 7q11.23 occur in approximately $90 \%$ of patients with Williams syndrome. Am J Hum Genet 1995;56:1156-61.

181. Li DY, Toland AE, Boak BB, et al. Elastin point mutations cause an obstructive vascular disease, supravalvular aortic stenosis. Hum Mol Genet 1997;6: 1021-8.

182. Ye M, Coldren C, Liang X, et al. Deletion of ETS-1, a gene in the Jacobsen syndrome critical region, causes ventricular septal defects and abnormal ventricular morphology in mice. Hum Mol Genet 2010;19:648-56.

183. Grossfeld PD, Mattina T, Lai Z, et al. The 11q terminal deletion disorder: a prospective study of 110 cases. Am J Med Genet A 2004;129A:51-61.

184. Greenway SC, Pereira AC, Lin JC, et al. De novo copy number variants identify new genes and loci in isolated sporadic tetralogy of Fallot. Nat Genet 2009;41:931-5.

185. Fakhro KA, Choi M, Ware SM, et al. Rare copy number variations in congenital heart disease patients identify unique genes in left-right patterning. Proc Natl Acad Sci U S A 2011;108:2915-20.

186. Warburton D, Ronemus M, Kline J, et al. The contribution of de novo and rare inherited copy number changes to congenital heart disease in an unselected sample of children with conotruncal defects or hypoplastic left heart disease. Hum Genet 2014;133:11-27.

187. Hitz MP, Lemieux-Perreault LP, Marshall C, et al. Rare copy number variants contribute to congenital left-sided heart disease. PLoS Genet 2012;8:e1002903.

188. Glidewell SC, Miyamoto SD, Grossfeld PD, et al. Transcriptional impact of rare and private copy number variants in hypoplastic left heart syndrome. Clin Transl Sci 2015;8:682-9.

189. Soemedi R, Wilson IJ, Bentham J, et al. Contribution of global rare copy-number variants to the risk of sporadic congenital heart disease. Am J Hum Genet 2012;91:489-501.

190. Prendiville T, Jay PY, Pu WT. Insights into the genetic structure of congenital heart disease from human and murine studies on monogenic disorders. Cold Spring Harb Perspect Med 2014;4.

191. McCulley DJ, Black BL. Transcription factor pathways and congenital heart disease. Curr Top Dev Biol 2012;100:253-77.

192. Bruneau BG. Signaling and transcriptional networks in heart development and regeneration. Cold Spring Harb Perspect Biol 2013;5:a008292.

193. Zaidi S, Choi M, Wakimoto H, et al. De novo mutations in histone-modifying genes in congenital heart disease. Nature 2013;498:220-3.

194. Shirley MD, Tang H, Gallione CJ, et al. Sturge-Weber syndrome and port-wine stains caused by somatic mutation in GNAQ. N Engl J Med 2013;368:1971-9.

195. van der Maarel SM, Deidda G, Lemmers RJ, et al. De novo facioscapulohumeral muscular dystrophy: frequent somatic mosaicism, sex-dependent phenotype, and the role of mitotic transchromosomal repeat interaction between chromosomes 4 and 10. Am J Hum Genet 2000;66:26-35.

196. Messiaen L, Vogt J, Bengesser K, et al. Mosaic type-1 NF1 microdeletions as a cause of both generalized and segmental neurofibromatosis type-1 (NF1). Hum Mutat 2011;32:213-9.

197. Prabhu S, Jenny B, James H, et al. Mosaic 22q11.2 deletion and tetralogy of Fallot with absent pulmonary valve: an unreported association. World J Pediatr Congenit Heart Surg 2015;6:342-5. 